\title{
Vestibular mapping in patients with unilateral peripheral-vestibular deficits.
}

\author{
Tarnutzer, Alexander A ; Bockisch, Christopher J ; Buffone, Elena ; Weber, Konrad P
}

\begin{abstract}
OBJECTIVE To test the hypothesis that patterns of semicircular canal (SCC) and otolith impairment in unilateral vestibular-loss depend on the underlying disorders, we analyzed peripheralvestibular function of all five vestibular sensors. METHODS Retrospective case-series. Screening of the hospital video-head-impulse test database $(\mathrm{n}=4983)$ for patients with unilaterally impaired SCC-function who also received ocular vestibular-evoked myogenic-potentials and cervical vestibular-evoked myogenicpotentials $(n=302)$. Frequency of impairment of vestibular end-organs (horizontal/anterior/posterior SCC, utriculus/sacculus) was analyzed with hierarchical cluster-analysis and correlated with the underlying etiology. RESULTS Acute vestibular-neuropathy (AVN) (37.4\%, 113/302), vestibular schwannoma $(18.2 \%, 55 / 302)$ and acute cochleo-vestibular neuropathy $(6.6 \%, 20 / 302)$ were most frequent. Horizontal SCC-impairment $(87.4 \%, 264 / 302)$ was more frequent $(\mathrm{p}<0.001)$ than posterior $(47.4 \%, 143 / 302)$ and anterior $(37.8 \%, 114 / 302)$ SCC-impairment. Utricular damage $(58 \%, 175 / 302)$ was noted more often $(\mathrm{p}=0.003)$ than saccular impairment $(32 \%, 98 / 302)$. On average $2.6(95 \%-\mathrm{CI}=2.48-2.78)$ vestibular sensors were deficient, with higher numbers ( $p$ 0.017) for acute cochleo-vestibular neuropathy and vestibular schwannoma than for AVN, Menière's disease and episodic-vestibular-syndrome. In hierarchical cluster-analysis, early mergers (posterior SCC/sacculus; anterior SCC/utriculus) pointed to closer pathophysiological association of these sensors, whereas the late merger of the horizontal canal indicated a more distinct state. CONCLUSIONS While the extent and pattern of vestibular impairment critically depended on the underlying disorder, more limited damage in AVN and Menière's disease was noted, emphasizing the individual range of loss-of-function and the value of vestibular-mapping. Likely, both the anatomical properties of the different vestibular end-organs and their vulnerability to external factors contribute to the relative sparing of the vertical canals and the sacculus.
\end{abstract}

DOI: https://doi.org/10.1212/WNL.0000000000010812

Posted at the Zurich Open Repository and Archive, University of Zurich

ZORA URL: https://doi.org/10.5167/uzh-192435

Journal Article

Accepted Version

Originally published at:

Tarnutzer, Alexander A; Bockisch, Christopher J; Buffone, Elena; Weber, Konrad P (2020). Vestibular mapping in patients with unilateral peripheral-vestibular deficits. Neurology, 95(22):2988-3001.

DOI: https://doi.org/10.1212/WNL.0000000000010812 


\section{Neurology"}

The most widely read and highly cited peer-reviewed neurology journal

The Official Journal of the American Academy of Neurology

Neurology Publish Ahead of Print

DOI: $10.1212 /$ WNL.0000000000010812

\section{Vestibular mapping in patients with unilateral peripheral-vestibular deficits}

Alexander A. Tarnutzer MD (1,2,3,4), Christopher J. Bockisch PhD $(2,3,4,5,6)$, Elena Buffone (3) and Konrad P. Weber MD $(2,3,4,5)$

\section{$\underline{\text { Affiliations }}$}

(1) Cantonal Hospital Baden, Baden, Switzerland

(2) Faculty of Medicine, University of Zurich, Zurich, Switzerland

(3) Department of Neurology, University Hospital Zurich, Zurich, Switzerland

(4) Clinical Neuroscience Center, Zurich, Switzerland

(5) Department of Ophthalmology, University Hospital Zurich, Zurich, Switzerland

(6) Department of Otorhinolaryngology, University Hospital Zurich, Zurich, Switzerland

Corresponding author:

Alexander A. Tarnutzer

Email: alexander.tarnutzer@ksb.ch

Statistical analysis: performed by Dr. A. Tarnutzer, MD. Neurology, Cantonal Hospital of Baden.

Study funding: No targeted funding reported.

Neurology ${ }^{\circledR}$ Published Ahead of Print articles have been peer reviewed and accepted for publication. This manuscript will be published in its final form after copyediting, page composition, and review of proofs. Errors that could affect the content may be corrected during these processes. 
Statistics:

Character count of the title (including spaces): 77

Word count of the abstract: 250

Word count of the manuscript: 4500

Number of tables: 2

Number of figures: 5

Number of citations: 50

Supplemental data: doi:10.5061/dryad.1jwstajrr

Key words: video-head-impulse testing, vestibular-evoked myogenic potentials, unilateral vestibular loss, hierarchical cluster analysis.

disclosure

Dr. A. Tarnutzer reports no disclosures relevant to the manuscript

Dr. C. Bockisch reports no disclosures relevant to the manuscript

Mrs E. Buffone reports no disclosures relevant to the manuscript

Dr. K. Weber was supported by the Swiss National Science Foundation [320030_166346] and the Uniscientia Stiftung, Vaduz, Liechtenstein. He acts as an unpaid consultant and has received funding for travel from Otometrics. 


\section{Abstract}

Objective: To test the hypothesis that patterns of semicircular canal (SCC) and otolith impairment in unilateral vestibular-loss depend on the underlying disorders, we analyzed peripheral-vestibular function of all five vestibular sensors.

Methods: Retrospective case-series. Screening of the hospital video-head-impulse test database ( $\mathrm{n}=4983$ ) for patients with unilaterally impaired SCC-function who also received ocular vestibular-evoked myogenic-potentials and cervical vestibular-evoked myogenicpotentials $(\mathrm{n}=302)$. Frequency of impairment of vestibular end-organs (horizontal/anterior/posterior SCC, utriculus/sacculus) was analyzed with hierarchical clusteranalysis and correlated with the underlying etiology.

Results: Acute vestibular-neuropathy (AVN) $(37.4 \%, 113 / 302)$, vestibular schwannoma $(18.2 \%, 55 / 302)$ and acute cochleo-vestibular neuropathy $(6.6 \%, 20 / 302)$ were most frequent. Horizontal SCC-impairment $(87.4 \%, 264 / 302)$ was more frequent $(\mathrm{p}<0.001)$ than posterior $(47.4 \%, 143 / 302)$ and anterior $(37.8 \%, 114 / 302)$ SCC-impairment. Utricular damage (58\%, 175/302) was noted more often $(\mathrm{p}=0.003)$ than saccular impairment $(32 \%, 98 / 302)$. On average $2.6(95 \%-\mathrm{CI}=2.48-2.78)$ vestibular sensors were deficient, with higher numbers $(\mathrm{p} \leq 0.017)$ for acute cochleo-vestibular neuropathy and vestibular schwannoma than for AVN, Menière's disease and episodic-vestibular-syndrome. In hierarchical cluster-analysis, early mergers (posterior SCC/sacculus; anterior SCC/utriculus) pointed to closer pathophysiological association of these sensors, whereas the late merger of the horizontal canal indicated a more distinct state.

Conclusions: While the extent and pattern of vestibular impairment critically depended on the underlying disorder, more limited damage in AVN and Menière's disease was noted, emphasizing the individual range of loss-of-function and the value of vestibular-mapping. Likely, both the anatomical properties of the different vestibular end-organs and their 
vulnerability to external factors contribute to the relative sparing of the vertical canals and the sacculus.

\section{INTRODUCTION}

About 3-6\% of all emergency consultations are attributed to dizziness/vertigo, ${ }^{1,2}$ resulting in $>5$ million visits in the US per year, ${ }^{3}$ with an underlying oto-vestibular pathology in about one third. ${ }^{1}$ Thus, in the diagnostic workup, assessing peripheral-vestibular function is essential. While at the bedside the integrity of the horizontal vestibulo-ocular reflex (VOR) can be assessed reliably using the head-impulse test, ${ }^{4}$ deficits of the vertical semicircular canals (SCC) or the otolith organs are often difficult to identify. New techniques as the videohead-impulse test ${ }^{5}$ and vestibular-evoked myogenic-potentials (VEMPs ${ }^{6}$ ) offer detailed mapping of all five vestibular sensors. With respect to the underlying cause of unilateralvestibular loss (UVL), different patterns can be predicted, which may prove useful in the differential diagnosis. For example, for acute-vestibular neuropathy (AVN), isolated or combined involvement of the superior and inferior branch of the vestibular nerve is possible. ${ }^{7}$ Whether this prediction based on the vestibular-nerve's anatomy is indeed reflected in clinical practice, however, has not been verified in a large cohort. Likewise, anterior-canal sparing reported in patients with unilateral vestibular schwannoma (VS) awaits confirmation. ${ }^{8,9}$

Here we aimed to correlate the pattern of vestibular impairment with the clinical (symptom-based) diagnosis by use of quantitative vestibular-testing. We hypothesize that typical pathophysiology-based patterns of peripheral-vestibular loss are found in part of the affected patients only, with patchier vestibular loss in the remaining patients. Therefore, the state of certain vestibular sensors may have a stronger predictive value for certain disorders as VS, AVN or Menière's disease (MD). 


\section{MATERIAL AND METHODS}

We retrospectively screened the vHIT-database of the University Hospital Zurich (search-period=10/2012-02/2018) for patients with unilateral peripheral-vestibular deficits in

1 SCC that had received testing of all six SCCs and both otolith organs. Selection criteria in this single-center study were confirmed unilateral peripheral-vestibular deficits in $\geq 1 \mathrm{SCC}$ (vHIT) and completed ocular/cervical VEMPs at the same time. Patients with bilateralperipheral-vestibular deficits or bilaterally-normal findings and patients with incomplete testing were excluded. No inclusion/exclusion was made based on the underlying diagnosis or symptom duration.

\section{Standard Protocol Approvals, Registrations, and Patient Consents}

The study protocol was approved by the Cantonal Ethics Committee Zurich (protocol=2018-00224). As requested by national laws, all subjects included January $1^{\text {st }} 2016$ or later provided written general-consent for the use of health-related data for research purposes.

\section{vHIT recording procedure}

We required 20 valid head-impulses for each SCC. ${ }^{10}$ For video-oculography, commercially available vHIT-goggles (Otometrics, Natus Medical Denmark ApS, Taastrup, Denmark) were used. Horizontal and vertical position of the right eye was measured (frequency $=250 \mathrm{~Hz}$ ) and angular head-velocity was determined by three orthogonal minigyroscopes.

\section{Vestibular-evoked myogenic-potentials recording procedure}

We reviewed otolith function as assessed by cervical VEMPs (cVEMPs, saccular testing) and ocular VEMPs (oVEMPs, utricular testing). Calibrated headphones (Telephonics 
TDH-39P; Telephonics Corp., Farmingdale, NY) were used to apply air-conducted sound stimuli $\left(500 \mathrm{~Hz}, 6 \mathrm{~ms}\right.$ tone-bursts at $90-100 \mathrm{~dB}$ normal-hearing level, 200 bursts $\left.^{11}\right)$ monaurally to the right and left ear for cVEMPs. ${ }^{12}$ In case of inconclusive/negative air-conducted cVEMPs, we obtained bone-conducted cVEMPs. Vibrations (unshaped $500 \mathrm{~Hz}$ bursts, interaural accelerations $\cdot 0.1 \mathrm{~g}$, duration $=4 \mathrm{~ms}, 200$ stimuli) were applied using a Minishaker (Model 4810, Brüel \& Kjaer, P/L, Naerum, Denmark) placed near Fz. ${ }^{13}$ To improve reproducibility of measurements and to reduce noise from asymmetric muscle tension, response-amplitudes were normalized. ${ }^{14,} 15$ Therefore, values for air- and bone-conducted cVEMPS are unitless. Only responses obtained at the highest stimulus-intensity applied were considered.

Bone-conducted oVEMPs (unshaped $500 \mathrm{~Hz}$ bursts, inter-aural accelerations $\cdot 0.1 \mathrm{~g}$, duration $=4 \mathrm{~ms}, 200$ stimuli) were applied by the same Minishaker. ${ }^{13}$ Stimuli were recorded with surface electrodes placed beneath the eyes during up-gaze. ${ }^{12}$ oVEMP-responses are crossed and we always refer to the side of utricular loss. ${ }^{16,17}$

\section{Patient-identification and data analysis}

Eye- and head-velocity traces were retrieved and peak head velocities were calculated to identify possible canal-dependent differences in vHIT-measurement performance. We re-analyzed angular VOR (aVOR) gains using Otosuite 4.0 (Otometrics). vHIT-gain was calculated as the ratio between the area over the curve of de-saccaded eyevelocity over head-velocity from the beginning of the head-impulse until eye-velocity crossed $0 \%$ again, corresponding to a de-saccaded position-gain. ${ }^{18}$ Saccades were defined as 'overt', if their onset occurred after head-velocity crossed zero after the head-impulse. Cumulative overt catch-up saccade-amplitude per trial was calculated for each SCC individually by 
adding the amplitudes of all overt saccades and dividing them by the respective number of trials in which they occurred. ${ }^{19-21}$

Peripheral-vestibular hypofunction was defined as a reduction in aVOR-gain and/or the occurrence of compensatory saccades. For gains, we adhered to the cut-off values of 0.8 (horizontal canals) and 0.7 (vertical canals) proposed by the manufacturer. Previously cut-off values suggested that cumulative saccade-amplitudes above $0.7-0.8 \%$ trial indicate loss-offunction of the SCC tested. ${ }^{19,22}$ We adhered to the cut-off value $\left(0.73^{\circ} /\right.$ trial $)$ proposed by our group, ${ }^{19}$ as the same statistical approach was used. Thus, presence of catch-up saccades qualified for abnormality even if the aVOR-gain was normal.

The underlying cause of UVL, symptom-duration and treatment site (emergencydepartment, hospital, outpatient general/specialty clinic) were retrieved from the patients' files. Besides vestibular-related diagnoses as MD, AVN with/without accompanying cochlear symptoms, cerebello-pontine angle (CPA) masses (including VS) and superior semicircularcanal dehiscence syndrome (SSCDS), files were screened for status-post CNS-infections, benign paroxysmal positional vertigo (BPPV) and traumatic brain-injury (TBI). Patients who received purely descriptive diagnoses as episodic vestibular syndrome (EVS), gait-imbalance or polyneuropathy (PNP) were assigned to separate groups.

We followed the AAO-HNS 1995 guidelines for diagnosing MD. ${ }^{23}$ Diagnosis of cholesteatoma was based on ENT-assessment and appropriate CT-imaging. MR-imaging was required to confirm CPA-masses, vestibular paroxysmia or central causes. For CPA-masses, a distinction was made between VS, other causes (e.g. epidermoid cysts, hemangioma, meningioma) and neurofibromatosis II. For SSCDS, superior-canal dehiscence on temporalbone CT-imaging and clinical symptoms consistent with the syndrome (i.e. sound-/pressureinduced vertigo) and physiological evidence for a third mobile-window were required. ${ }^{24}$ The diagnosis of AVN was based on clinical grounds (i.e., a single episode of acute-onset, prolonged vertigo/dizziness and spontaneous nystagmus) and - if available - on vestibular- 
testing in the acute stage. ${ }^{25}$ For acute cochleo-vestibular neuropathy (ACVN), in addition a new-onset hearing-loss ipsilesionally was required.

Two experienced neuro-otologists (KPW, AAT) independently reviewed all vHITtraces according to the criteria of peripheral-vestibular function outlined above, considering the overall pattern of the vHIT-traces including artefacts such as goggle-slippage and resulting false-high aVOR-gains also. Inter-rater agreement for individual canal function (normal vs. pathological) was 0.95 (Cohen's kappa). ${ }^{26}$ Discordant ratings were resolved by discussion.

For assessing utricular and saccular integrity, we focused on VEMP-amplitude asymmetry-ratio (=AR, left vs. right side) ${ }^{27}$ as this is considered the most robust parameter. AR-values of $>30 \%$ were considered abnormal. This was based on normative values from our laboratory and on the range of cut-off values previously proposed. ${ }^{16}$

Results from cases with a left-sided vestibular impairment were mirrored, so that the right side was always the affected side. MATLAB and SPSS 26 (IBM, Armonk, NY) were used for statistical analyses. Fisher's exact test with Bonferroni-correction for multiple tests was applied to determine significant differences in the frequency of individual conditions. We applied a generalized linear model (GLM, SPSS 26) to analyze aVOR-gains, cumulative saccade-amplitudes and effects of the underlying disorders on the extent of peripheralvestibular impairment. Fisher's least-significant-difference (LSD) method was used to correct for multiple comparisons. The level of significance for all statistical tests was $\mathrm{p}=0.05$.

Principal-component-analysis (PCA) was used for comparisons between two dependent variables. ${ }^{28}$ The coefficient-of-determination $\left(\mathrm{R}^{2}\right)$ was used to assess the goodnessof-fit. A correlation between two variables was considered significant whenever the 95\%confidence-interval (95\%-CI) of the slope did not include zero.

For visualization of coherent patterns of vestibular-impairment we implemented cluster heat-maps. ${ }^{29}$ For each vestibular sensor and subject, the functional state was retrieved. 
We applied hierarchical clustering (MATLAB, clustergram.m) to obtain heat-maps with dendrograms of the entire data set. ${ }^{30}$ The heat-map was clustered by Euclidean distance. We selected this clustering algorithm because in Euclidean space each object is equally weighted and since it is amongst the most frequently used algorithms in hierarchical clustering. The data was standardized along the data columns, i.e. for the individual results from single subjects. This standardized value was then depicted in a range of colors between 1.5 (dark blue) to -1.5 (dark red). For individual patients only one intensity of blue and red (being more or less dark/light) were used as only two functional states ( 1 =intact, $0=$ deficient) were possible. Cluster dendrograms in our data set indicate those patients ( $\mathrm{x}$-axis) and vestibular sensors (y-axis) that are least different, as these groups cluster together first. More distinct clusters group later. No minimal cluster size was predefined when performing the hierarchical cluster analysis, however, for subsequently identifying the most common patterns, minimal cluster size was set to 25 .

\section{Data Availability}

Anonymized data will be shared on request from any qualified investigator. 


\section{RESULTS}

From 4983 patients stored in the vHIT-database, 326 patients with reported UVL and complete vestibular mapping were identified and their vHIT-recordings were reviewed (see Figure 1). Twenty-four patients were excluded due to bilateral peripheral-vestibular deficits $(n=12)$ or bilaterally-normal peripheral-vestibular function $(n=12)$. Three-hundred-two patients were included, mostly seen in specialized outpatient clinics (Table 1). The most frequent disorders were AVN (113/302, 37.1\%), VS (55/302, 18.5\%) and EVS (46/302, 16.7\%). Delay from symptom-onset (being vertigo/dizziness or gait imbalance in all but 2 patients with VS that reported ipsilesional hearing-loss only) was very variable, ranging from $<1$ day to $>50$ years $(5.0[4.0-7.0] \pm 4.9$ months, median $(95 \% \mathrm{CI}) \pm$ median absolute deviation (MAD), Table 1). Overall shortest time from symptom-onset was noted for AVN and ACVN. Single-subject data is shown in Figure 2 for a patient with left-sided superior-branch AVN.

\section{Distribution of affected SCCs and otolith organs}

Fractions of SCCs rated as impaired were significantly ( $\mathrm{p}<0.001$, Fisher's exact test) larger for the horizontal $(264 / 302,87.4 \%)$ than the posterior $(143 / 302,47.4 \%)$ and anterior $(114 / 302,37.8 \%)$ SCC, whereas no difference between the anterior and posterior SCCs was noted (Figure 3A). Statistical analysis revealed a main effect for the SCC on aVOR-gains $(\mathrm{df}=5$, chi-square=161.377, $\mathrm{p}<0.001$ ). Pairwise comparisons (affected side) demonstrated higher gains for the anterior SCC compared to the horizontal $(\mathrm{p}<0.001)$ and posterior $(\mathrm{p}<0.001)$ SCC, whereas there was only a trend towards larger gains for the posterior canal 
compared to the horizontal canal $(\mathrm{p}=0.055)$ (Figure 3B). Likewise, there was a main effect for the SCC on cumulative saccade-amplitudes $(\mathrm{df}=5$, chi-square $=298.415, \mathrm{p}<0.001)$. Pairwise comparisons demonstrated higher saccade amplitudes for the horizontal SCC compared to the anterior $(\mathrm{p}<0.001)$ and posterior $(\mathrm{p}<0.001)$ SCC and higher saccade-amplitudes for the posterior SCC compared to the anterior SCC $(\mathrm{p}=0.015)$ on the affected side (Figure 3C). The fraction of ipsilesional SCCs rated as overall abnormal but showing normal aVOR-gains was $12.5 \%(33 / 264), 13.2 \%(15 / 114)$ and $24.5 \%$ (35/143) for the horizontal, anterior and posterior SCC.

Individual mean peak-head velocities were higher for the lateral (left=159.6 (155.9$163.3,95 \% \mathrm{CI}) \pm 32.7 \% \mathrm{sec}$, right $=151.0(147.3-154.8) \pm 33.1 \% \mathrm{sec})$ than the anterior $(\mathrm{left}=126.5$ $(123.2-129.7) \pm 28.7 \%$ sec, right $=132.7(129.5-135.9) \pm 28.0 \% \mathrm{sec})$ and posterior $(\mathrm{left}=129.7$ $(126.9-132.4) \pm 24.3 \%$ sec, right $=122.7(119.6-125.8) \pm 27.7 \% / \mathrm{sec})$ canals. Statistical analysis of peak head-velocity values showed a main effect for the SCC $(\mathrm{df}=5$, chi-square $=192.1$, $\mathrm{p}<0.001)$. Pairwise comparisons demonstrated larger peak head-velocity values for the rightanterior SCC than for the right-posterior $\mathrm{SCC}(\mathrm{p}=0.001)$, whereas values were not different $(p=0.121)$ for the left-anterior and left-posterior SCC.

Further analysis on the frequency of affected SCCs in subgroups with $\geq 5$ samples showed clearly different patterns. Whereas for all 10 subgroups the horizontal canal was affected most frequently, the anterior canal was relatively spared when compared to the average number of affected horizontal/posterior canals or to the horizontal SCC only in more than $50 \%$ of cases in six subgroups (Table $2 \mathrm{~A}$ ).

Focusing on otolith function, 32\% (98/302) of all patients showed ipsilesional impairment of utricular function only, whereas $7 \%$ (21/302) presented with isolated ipsilesional saccular loss-of-function (Table 2B). Ipsilesional impairment of both utricular and saccular function was noted in 77/302 (26\%). In comparison, the rate of utricular impairment was significantly $(58 \%(175 / 302)$ vs. $32 \%(98 / 302), \mathrm{p}<0.001)$ higher than that of saccular 
impairment. Ipsilesional utricular and saccular responses were absent in 106/302 (35\%) and in 55/302 (18\%) patients, respectively.

/* Figure 3 about here */

\section{Disease-specific patterns in vestibular impairment}

Isolated loss-of-function of one horizontal SCC was most frequent (53/302, 18\%), followed by combined impairment of the horizontal and anterior SCC and the utriculus $(37 / 302,12 \%)$ and impairment of all five vestibular sensors $(35 / 302,12 \%)$ (Table $2 \mathrm{C}$, Figure 3D).

\section{$A V N$ and $A C V N$}

In AVN-patients, most frequently the horizontal and anterior SCC and the utriculus were impaired $(34 / 113,30 \%)$, followed by isolated horizontal-canal loss-of-function $(17 / 113$, $15 \%)$ and horizontal-canal plus utricular loss-of-function $(13 / 113,12 \%)$ (Figure 4A). Overall, patterns that match involvement of some $(38 / 113,34 \%)$ or all structures $(34 / 113,30 \%)$ innervated by the superior-branch of the vestibular nerve were identified in $64 \%$. A pattern consistent with damage restricted to (parts of) the inferior-branch of the vestibular nerve - was found in $4 / 113(4 \%)$ patients, with all 4 presenting with isolated loss-of-function of the posterior SCC (Figure 4A). In the remaining 37 cases, sensors innervated from both the inferior and superior branch were damaged, with loss-of-function of all five sensors in 7/113 (6\%). Compared to utricular impairment, saccular loss-of-function was less frequently observed $(66 \%(75 / 113)$ vs. $21 \%(24 / 113), \mathrm{p}<0.001$, Table 2B). In patients with ACVN, involvement of all five sensors $(6 / 20,30 \%)$ or of the horizontal and posterior SCC and the utriculus $(3 / 20,15 \%)$ were noted most often (Figure 4B). 
/* Figure 4 about here */

\section{VS and other CPA-tumors}

In VS-patients most frequently all five sensors were impaired $(14 / 55,26 \%)$, followed by loss-of-function of all sensors but the anterior canal $(10 / 55,18 \%)$ (Figure 4C). A single SCC (horizontal or posterior) was damaged in $6 / 55$ (11\%). Utricular impairment was noted in $73 \%$ (40/55), while saccular loss-of-function was identified in 56\% (31/55). In patients with other CPA-tumors, four out of five sensors were affected in 4/9 (44\%) cases, with either the sacculus or the anterior canal spared (Figure 4D).

For all 55 VS-patients the maximal tumor diameter was retrieved, averaging at $19.0 \mathrm{~mm}[16.4-21.6,95 \% \mathrm{CI}] \pm 9.4 \mathrm{~mm}( \pm 1 \mathrm{SD}$; range $=4-50 \mathrm{~mm} ;$ missing data=2). We hypothesized that the tumor-size correlates with the extent of vestibular loss-of-function. We restricted the analysis to those 42 VS-patients that were untreated. PCA demonstrated a significant correlation between the tumor-diameter and the number of vestibular sensors impaired $\left(\mathrm{R}^{2}=0.59\right.$, slope $\left.=0.15,95 \%-\mathrm{CI}=0.12-0.18\right)$.

For VS and other CPA-tumors results from pure-tone audiogram testing were retrieved. Based on CPT-AMA guidelines, hearing-loss was defined as a CPT-value $>20 \%{ }^{31}$ Seventy-seven percent of the VS-patients $(41 / 53$, missing data=2) and 55\% of the other CPAtumors patients $(5 / 9)$ demonstrated ipsilesional hearing-loss $(\mathrm{p}=0.219)$.

\section{Structural inner-ear damage}

In patients with $\mathrm{MD}(\mathrm{n}=16$, recorded in-between attacks), involvement of a single SCC was most frequent (Figure 4E). Only 2/16 cases showed involvement of the anterior canal. Otolith impairment was noted in 9 out of 16 cases (Table 2B). For TBI, deficits were reaching from impairment of all five sensors to involvement of a single SCC and the utriculus 
or a single SCC (Figure 4F). Patients with a history of inner-ear infection showed varying extent of vestibular-damage. Whereas extensive damage was noted in three, the others showed damage restricted to one or two sensors (Figure 4G).

\section{EVS and gait-imbalance}

In EVS-patients most frequently a single SCC (horizontal or posterior) was impaired, followed by involvement of the horizontal SCC and the utriculus (Figure 4H). Otolith deficits were uncommon (Table 2B). Patients who reported gait-imbalance showed impairment of a single SCC in the majority of cases (Figure 4I).

\section{Extent of vestibular end-organ damage}

The average number $( \pm 1 \mathrm{SD})$ of damaged sensors was $2.6[2.5-2.8,95 \%$ $\mathrm{CI}] \pm 1.3$. We noted a main effect of the underlying diagnosis $(\mathrm{df}=9$, chi-square $=88.254$, $\mathrm{p}<0.001)$. Pairwise comparisons demonstrated higher $(\mathrm{p} \leq 0.017)$ numbers of affected sensors for patients with ACVN, VS and other CPA-masses than for those with AVN, TBI, MD, EVS, central causes and gait-imbalance. Compared to patients with UVL related to EVD, gait-imbalance or central causes, patients with AVN showed involvement of significantly more sensors $(\mathrm{p} \leq 0.017)$ (Figure $3 \mathrm{E})$.

\section{Hierarchical cluster analysis}

The dendrogram illustrating the clustering of the vestibular sensors (Figure 5) indicated that mergers occurred first for the posterior canal and the sacculus and for the anterior canal and the utriculus, respectively. At the next higher level of merger, these two pairs were combined, whereas the horizontal canal was added last. The top dendrogram indicated seven clusters with at least 25 nodes (i.e. patients). 
The distinguishing feature in node A ( $n=34$, most frequent: AVN ( $n=8), \operatorname{VS}(n=6)$, EVS ( $n=6)$ ) was the state of the horizontal and the posterior canal (being impaired in all), whereas in node B $(n=35$, most frequent: EVS $(n=11)$, VS $(n=8), \operatorname{AVN}(n=6))$ it was the impairment of the posterior canal only and relative sparing of the other sensors that was critical. In contrast, for node $C(n=43)$ the state of the anterior canal was the distinguishing feature, being intact in all (most frequent: VS $(n=14), \operatorname{AVN}(n=10)$, other CPA-masses $(n=6))$. For node D ( $n=30$, most frequent: $\operatorname{AVN}(n=13)$, EVS $(n=6)$, VS $(n=5))$ the distinguishing feature was the state of the horizontal canal and the utriculus, being impaired in all, while the other sensors were spared. In node $\mathrm{E}(\mathrm{n}=37, \mathrm{AVN}(34 / 37))$ impairment of both the anterior and the horizontal canal and the utriculus was mandatory. This pattern is consistent with the innervation/vascular supply by the superior-branch of the vestibular nerve/artery. In node F $(n=35)$ with no distinguishing features on the heat map all patients with impairment of all five sensors were included, with VS $(n=14), \operatorname{AVN}(n=7)$ and $\operatorname{ACVN}(n=6)$ representing the most frequent diagnoses. In contrast, patients assigned to node $G(n=53)$ presented with isolated impairment of the horizontal canal and received a diagnosis of EVS $(n=17)$ or AVN $(n=16)$ most often.

/* Figure 5 about here */ 


\section{Discussion}

Comprehensive vestibular-mapping in a large cohort of patients with unilateral vestibular-deficits comprised the entire spectrum from single SCC-deficits to complete UVL. Patterns of vestibular deficits were distinct for different underlying disorders, involving the highest number of vestibular sensors for ACVN, VS and other CPA-masses, whereas numbers were significantly smaller in AVN and MD. While the underlying pathomechanisms and the vestibular anatomy were important parameters, we often noted incomplete patterns, emphasizing the range of deficits even within anatomically clearly defined disorders such as AVN.

\section{Disease-specific SCC-patterns in UVL}

\section{$A V N$ and $A C V N$}

For AVN, patterns that matched involvement of some or all structures innervated by the superior vestibular-nerve (SVN) were identified in $64 \%$ of all cases, which was higher than previously reported $($ range $=40-42 \%) .{ }^{32,33}$ Thus, we noted lower rates of combined SVN and inferior-branch vestibular neuropathy (IVN) than others (33\% vs. 55-56\%). ${ }^{32,33}$ The higher rate of combined AVN in previous studies could be related to a selection bias, overweighting more severely affected patients. ${ }^{32}$ The presence of hearing-loss, as required for ACVN, was associated with significantly more extensive vestibular damage as compared to the AVN-group. None of our AVN-patients presented with the 'classical' IVN-pattern of combined posterior canal and saccular loss only; ${ }^{34}$ those four patients (reflecting $4 \%$ of all AVN-cases) with SCC loss-of-function restricted to the posterior canal had normal saccular function ipsilaterally. In the literature, $2-5 \%$ of all AVN-patients showed a partial or complete IVN-pattern, ${ }^{32,33,35}$ matching our numbers. 
In our AVN-subgroup all but six patients showed impairment of the horizontal SCC, whereas anterior canal-function was relatively spared (107 vs. 63, p<0.001), emphasizing that the pattern linked to SVN is often incomplete. Our findings, however, are in contrast with several AVN-studies, showing no significant sparing of anterior-canal function. ${ }^{32,}{ }^{36}$ In the study by Büki the fraction with isolated horizontal-canal impairment was clearly lower than in our study (4/44 vs. 29/112). This might be related to the definition of canal-impairment. Whereas these authors required a gain-reduction, we considered the presence of catch-up saccades (but still normal gain) as impairment as well. Likewise, another study reporting on 40 AVN-patients showed no anterior-canal sparing. ${ }^{33}$ These differences are potentially related to distinct video-oculography systems used (Ulmer vs. Otometrics) and the aVOR-analysis performed (with or without taking cumulative saccade-amplitudes into consideration). In another study, rates in horizontal and anterior canal-impairment were not significantly different. ${ }^{37}$ In this study the inclusion criteria were based on caloric-irrigation and cVEMPs, thus cannot directly be compared with our approach.

\section{VS and other CPA-tumors}

In patients with VS or other CPA-tumors, who often demonstrated extensive vestibular damage, the number of impaired vestibular end-organs correlated with the tumor size, confirming previous reports. ${ }^{8}$ In the VS-subgroup, we noted significant anterior-canal sparing, with less than half as many anterior canals being affected compared to either posterior or horizontal canals. This is consistent with the literature. ${ }^{8,9}$

\section{Structural inner-ear damage}

In those patients with structural inner-ear damage, the range of vestibular end-organ damage depended on the underlying cause. While for MD more limited loss-of-function was noted, the range of impairment was variable for inner-ear infections and TBI. Previously, we 
reported anterior-canal sparing in patients with bilateral-vestibular-loss linked to aminoglycoside-exposure and MD, while this was not observed in vestibular-loss related to inner-ear infections. ${ }^{19}$ We predicted a similar pattern in UVL. This was confirmed in our unilateral MD-subgroup, with anterior-canal function being preserved in 13/15 patients (87\%). Relative sparing of anterior-canal function has been described in relation to posteriorcanal dysfunction: In a study with 90 patients with definitive unilateral MD, reduced vHITgains of the posterior canal were most frequent $(44 \%)$, whereas rates were significantly $(\mathrm{p}<0.001)$ lower for the horizontal $(13 \%)$ and anterior $(10 \%)$ canal. ${ }^{38}$ In another study with 36 patients with definitive unilateral MD, there was a trend to a higher fraction of posterior SCCimpairment than anterior or horizontal SCC-impairment. ${ }^{39}$ Thus, while the literature confirms higher rates of posterior-canal impairment compared to the anterior canal, the fraction of horizontal-canal impairment seems more variable. We noted no sparing of horizontal-canal function relative to posterior-canal function, which may be due to differences in patient selection. In our retrospective case-series patients were included based on abnormal vHITresults and not symptom presentation. Posterior SCC-impairment may result in more subtle symptoms, thus in these patients vHIT may not have been performed.

\section{EVS and gait-imbalance}

Patients with EVS or gait-imbalance most often showed impairment of a single SCC (usually the horizontal or posterior SCC). In these patients the association between clinical complaints and vestibular end-organ deficits identified is less stringent and may be coincidental or reflecting only one amongst several contributing factors. Conceptually, these patients may have previously suffered vestibular loss-of-function due to various causes (including AVN, TBI) that have not been identified and now present with residual vestibularimpairment. Furthermore, other disorders related to EVS such as vestibular migraine may present with more subtle aVOR-deficits. ${ }^{40-42}$ 


\section{Otolith function}

Two thirds of all UVL-patients had otolith deficits, with utricular loss-of-function (58\%) being significantly more frequent than saccular hypofunction (32\%). Relative sparing of saccular function could be related to the pathomechanisms of the disorders, e.g. with preferential utricular impairment in superior-branch AVN, which is much more frequent than inferior-branch AVN. ${ }^{43,44}$ Taylor reported higher rates of abnormal oVEMPs compared to cVEMPs for AVN (32\% vs. 16\%), matching our observations regarding relative rates (67\% vs. $21 \%$ ), albeit with smaller fractions of otolith impairment overall.

In the MD-subgroup, impairment-rates of the utriculus and sacculus were not significantly different. This is in contrast to previous reports of significantly higher rates of cVEMP-abnormalities. $^{45,46}$ cVEMP-abnormalities were reported in $37-54 \%$ of cases, ${ }^{46-48}$ being higher than the $25 \%$ reported here. Yarious conditions may provide potential explanations for these discrepancies. This includes relatively small sample sizes, patient selection, distinct stimulation protocols and variations in the selected parameters considered relevant for rating VEMP-integrity.

In our VS-patients, rates of utricular loss-of-function were slightly larger than for saccular hypofunction ( $73 \%$ vs. $56 \%$ ). These fractions are close to the ranges reported in the literature for oVEMPs (57-69\%) and cVEMPs (56-64\%). ${ }^{8,49}$

\section{Mechanisms of vertical canal-sparing in UVL}

Compared to the vertical SCCs, impairment of the horizontal SCC was significantly more frequent throughout the entire cohort and for several UVL-subgroups (VS, AVN, ACVN, MD, EVD). We can only speculate about the underlying cause of vertical-canal sparing in UVL. Both the anatomical organization of the vestibular nerve, the physiological properties of the different vestibular end-organs, and their vulnerability to external factors 
(including trauma, infection, toxic substances) may explain the relative sparing of the vertical SCCs. Specifically, the nerve fibers originating from the anterior SCC could be located more centrally within the vestibular nerve, thus being less prone to pressure due to a tumor or nerve swelling. Alternatively, recovery from damage may vary amongst the hair cells of the different SCCs or its nerve fibers.

\section{Pattern-identification in UVL using hierarchical cluster analysis}

The more similar state of the two pairs (posterior SCC-sacculus; anterior SCCutriculus) underlines the importance of the anatomical relationship of the vestibular endorgans (superior-branch vs. inferior-branch of the vestibular nerve and its vascular supply) for UVL. Combined damage of the horizontal and anterior SCC and the utriculus was almost always linked to AVN, matching current anatomical and pathophysiological concepts of AVN. Similarly, those subgroups predicted to have most extensive damage (ACVN, VS) were over-represented in the node indicating damage to all five sensors. On the other end of the spectrum, vestibular end-organ damage was restricted to the horizontal SCC in $18 \%$. Accordingly, cases with more vague clinical presentation (EVD) were over-represented in this node, but also AVN cases were assigned to it.

Overall, hierarchical cluster analysis facilitates pattern-recognition in UVL and emphasizes the broad range of vestibular end-organ damage across our study population and the subgroups. Thus, our data underlines the need for detailed vestibular-mapping of all five vestibular end-organs to identify the extent of damage appropriately.

\section{Limitations}

While the large sample size is a strength of our study, it has also several limitations. This includes the retrospective study design, the binary reduction of the functional state of the vestibular sensors to "impaired" vs. "spared" and the patient selection that depended on a 
single test (vHIT), requiring impairment of at least one SCC. Thus, we cannot make any conclusions on the prevalence of these diseases in the general population or on a potential selection bias as we do not have any numbers on the rejection rate for vestibular testing. The patients included did not receive a standardized clinical neuro-otologic examination and there were no prospectively defined diagnostic criteria for specific disorders. For MD, guidelines according to the AAO-HNS from 1995 were used as we included patients studied as early as 2012. Furthermore, a relatively large group of patients received a purely descriptive diagnosis as EVD or gait-imbalance.

We decided not to include a control group, but relied on normative values instead. While cut-off values for vHIT are well-defined and criteria for rating the functional state of single SCCs are established, parameters for oVEMPs and cVEMPS are more controversial. In vestibular laboratories, cut-off values and stimulation-parameters for VEMPs differ, making comparison with previous publications more complicated. This may explain different rates of otolith impairment reported by different research groups. 


\section{CONCLUSION}

The range of vestibular end-organ damage in patients with vHIT-confirmed UVL is broad and disease-dependent. Hierarchical cluster analysis was successfully implemented and facilitated pattern-recognition substantially. Specifically, more extensive vestibular end-organ damage was associated with ACVN and VS, whereas those patients with EVS or gaitimbalance presented with much more limited vestibular impairment. A combination of horizontal and anterior SCC impairment and utricular loss-of-function was highly predictive for AVN, confirming the pathophysiological link to the superior vestibular nerve and vascular supply. The underlying cause for the observed vertical-canal sparing remains open, with differences in the vulnerability of the sensors involved and their recovery representing potential mechanisms. 


\section{TABLES}

Table 1: epidemiologic aspects

\begin{tabular}{|c|c|c|}
\hline \multicolumn{3}{|l|}{ Table 1: epidemiologic aspects of UVL } \\
\hline & n $(\%)$ & \\
\hline \multicolumn{3}{|l|}{ Gender } \\
\hline Females & $137(45.4 \%)$ & \\
\hline Males & $165(54.6 \%)$ & \\
\hline \multicolumn{3}{|l|}{ Affected side } \\
\hline Right & $127(42.1 \%)$ & \\
\hline Left & $175(57.9 \%)$ & \\
\hline \multicolumn{3}{|l|}{$\operatorname{Age}(\operatorname{mean}[95 \% \mathrm{CI}] \pm 1 \mathrm{SD})[\mathrm{y}]$} \\
\hline Females & $55.3[$ 52.5-58.1] \pm 16.4 & \\
\hline Males & $56.5[54.3-58.8] \pm 14.7$ & \\
\hline \multicolumn{3}{|l|}{ Frequency of affected sensors } \\
\hline Horizontal SCC & $264(87.4 \%)$ & \\
\hline Anterior SCC & $114(37.8 \%)$ & \\
\hline Posterior SCC & $143(47.4 \%)$ & \\
\hline Utriculus & $175(58.0 \%)$ & \\
\hline Sacculus & $98(32.5 \%)$ & \\
\hline Clinical setting at the time of vestibular testing & & $\begin{array}{l}\text { Symptom duration (onset to vestibular } \\
\text { testing) }[\text { median }[95 \% \mathrm{CI}] \pm \text { MAD, range] }\end{array}$ \\
\hline Emergency department & $3(1.0 \%)$ & $1[<1-1] \pm 0$ days $(<1$ day to 1 day) \\
\hline Hospital & $41(13.6 \%)$ & $3[2-6] \pm 2$ days ( 1 day to 12 years $)$ \\
\hline Outpatient general clinic & $0(0.0 \%)$ & $\mathrm{NaN}$ \\
\hline Outpatient specialty clinic & $258(85.4 \%)$ & $7.0[5-12] \pm 6.7$ months ( 1 day to $>50$ years) \\
\hline \multicolumn{3}{|l|}{ Diagnosis } \\
\hline Acute vestibular neuropathy (AVN) & $113(37.4 \%)$ & 15 [7-45] \pm 14 days ( $<1$ day to 13 years) \\
\hline Unilateral vestibular schwannoma (VS)* & $55(18.2 \%)$ & $20.0[12-36] \pm 16.0$ months ( 15 days to 25 years) \\
\hline Episodic vestibular syndrome (EVD) & $46(15.2 \%)$ & $14.5[8-27] \pm 12.5$ months ( 15 days to 20 years) \\
\hline Acute cochleo-vestibular neuropathy (ACVN) & $20(6.6 \%)$ & $2.0[0.25-19] \pm 2.0$ months $(<1$ day to 28 years $)$ \\
\hline Menière's disease $(\mathrm{MD}) \dagger$ & $16(5.3 \%)$ & $\begin{array}{l}17.5[3-36] \pm 14.5 \text { months (1.5 months to } 10 \\
\text { years) }\end{array}$ \\
\hline Other causes $\ddagger$ & $16(5.3 \%)$ & $11.0[2-42] \pm 9.0$ months ( 15 days to 25 years) \\
\hline $\begin{array}{l}\text { Cerebello-pontine angle (CPA) mass other than } \\
\text { vestibular schwannoma§ }\end{array}$ & $9(3.0 \%)$ & $9.0[3-180] \pm 2.0$ months ( 3 months to 15 years) \\
\hline Traumatic brain injury & $8(2.6 \%)$ & $7.5[0.67-60] \pm 6.2$ months ( 20 days to 5 years $)$ \\
\hline Gait imbalance & $7(2.3 \%)$ & $\begin{array}{l}35.0[12-120] \pm 23.0 \text { months (12 months to } 10 \\
\text { years) }\end{array}$ \\
\hline Inner-ear infection & $6(2.0 \%)$ & $5.0[0-14] \pm 4.3$ months ( 1 day to 14 months) \\
\hline Central causes\| & $6(2.0 \%)$ & $9.0[1->600] \pm 6.5$ months ( 1 day to $>50$ years) \\
\hline all & $302(100.0 \%)$ & $5.0[4-7] \pm 4.9$ months $(<1$ day to $>50$ years $)$ \\
\hline
\end{tabular}

* A subset of patients had previously received surgical resection $(n=4)$, radiation therapy $(n=6)$, both radiation therapy and resection $(n=1)$, or gentamicin treatment before resection $(n=2)$ of the VS.

$\dagger$ None of the Menière's disease patients had received any ablation treatments such as neurectomy or labyrinthectomy. 
† Other causes included cholesteatoma $(n=3)$, bilateral schwannoma $(n=1)$, neurofibromatosis Typ II $(n=1)$, benign paroxysmal positional vertigo (BPPV) $(n=4)$, unclear $(n=2)$, vestibular-nerve dissection $(n=1)$, peripheral polyneuropathy (PNP) $(n=2)$, vestibular paroxysmia $(n=1)$ and superior semicircular canal dehiscence syndrome $(\operatorname{SSCDS})(\mathrm{n}=1)$.

$\S$ This included cerebello-pontine angle masses or intrameatal masses except confirmed vestibular schwannoma. Specifically, we assigned epidermoid cysts $(n=1)$, unclear intrameatal masses $(n=2)$, CPA-angle meningioma $(n=4)$ and schwannoma of other nerves (glossopharyngeal nerve $(n=1)$, facial nerve $(n=1)$ ) to this group.

|| Central causes included status post cerebellar hemorrhage $(n=1)$, neurodegenerative cerebellar ataxia $(n=1)$, status post dorsolateral medullary stroke on the right side $(n=1)$, acute bilateral cerebellar stroke $(n=1)$, Chiari Typ 1 malformation $(n=1)$ and superficial siderosis with cerebellar ataxia $(n=1)$. 
Table 2: Anterior canal sparing, utricular/saccular loss-of-function and most frequent combinations

\begin{tabular}{|c|c|c|c|c|c|c|c|c|c|c|c|c|}
\hline & & & & & & & & & & & & \\
\hline \multicolumn{5}{|c|}{ Part A: anterior canal sparing } & \multicolumn{5}{|c|}{ Part B: Utricular \& saccular function } & \multicolumn{3}{|c|}{ Part C: most frequent combinations } \\
\hline Disease group & $\begin{array}{l}\text { \# affected } \\
\text { hor } \\
\text { canals }\end{array}$ & $\begin{array}{l}\text { \# affected } \\
\text { ant canals }\end{array}$ & $\begin{array}{l}\text { \# affected } \\
\text { post canals }\end{array}$ & $\begin{array}{l}\text { Relative rate: } \\
\text { affected ant } \\
\text { canals vs. } \\
\text { average } \\
\text { affected hor } \\
\text { \& post canals }\end{array}$ & $\begin{array}{l}\text { Utricular } \\
\text { impairment } \\
\text { only }(\%)\end{array}$ & $\begin{array}{l}\text { Saccular } \\
\text { impairment } \\
\text { only }(\%)\end{array}$ & $\begin{array}{l}\text { Utricular } \\
\text { \& saccular } \\
\text { impairment } \\
(\%)\end{array}$ & $\begin{array}{l}\text { Utriculus } \\
\text { \& sacculus } \\
\text { spared } \\
(\%)\end{array}$ & $\begin{array}{l}\text { Fraction of } \\
\text { utricular vs. } \\
\text { saccular } \\
\text { impairment }\end{array}$ & $\begin{array}{l}\text { Most frequent } \\
\text { pattern }\end{array}$ & $\begin{array}{l}2^{\text {nd }} \text { most frequent } \\
\text { pattern }\end{array}$ & $\begin{array}{l}3^{\text {rd }} \text { most frequent } \\
\text { pattern }\end{array}$ \\
\hline $\begin{array}{l}\text { Acute vestibular } \\
\text { neuropathy }(\mathrm{n}=113)\end{array}$ & 107 & 63 & 27 & 0.94 & $56(49.6)$ & $5(4.4)$ & $19(16.8)$ & $33(29.2)$ & $\begin{array}{l}66 \% \text { vs. } 21 \%: \\
\mathrm{p}<0.001\end{array}$ & $\begin{array}{l}\text { All } 5 \text { sensors }(25 \%, \\
14 / 55)\end{array}$ & $\begin{array}{l}\text { Hor \& post SCC, } \\
\text { utriculus \& sacculus } \\
(18 \%, 10 / 55)\end{array}$ & $\begin{array}{l}\text { Hor SCC \& } \\
\text { utriculus }(9 \%, 5 / 55)\end{array}$ \\
\hline $\begin{array}{l}\text { Inner-ear infection } \\
(\mathrm{n}=6)\end{array}$ & 5 & 3 & 4 & 0.67 & $12(21.8)$ & $3(5.5)$ & $28(50.1)$ & $12(21.8)$ & $\begin{array}{l}73 \% \text { vs. } 56 \%: \\
p=0.110\end{array}$ & $\begin{array}{l}\text { Hor \& ant SCC \& } \\
\text { utriculus }(30 \% \text {, } \\
34 / 113)\end{array}$ & $\begin{array}{l}\text { Horizontal SCC only } \\
(15 \%, 17 / 113)\end{array}$ & $\begin{array}{l}\text { Hor SCC \& } \\
\text { utriculus }(12 \% \text {, } \\
13 / 113)\end{array}$ \\
\hline $\begin{array}{l}\text { Traumatic brain injury } \\
(\mathrm{n}=8)\end{array}$ & 6 & 3 & 3 & 0.67 & $10(21.7)$ & $4(8.7)$ & $4(8$. & $28(60.9)$ & $\begin{array}{l}30 \% \text { vs. } 17 \%: \\
p=0.221\end{array}$ & $\begin{array}{l}\text { All } 5 \text { sensors }(30 \% \text {, } \\
6 / 20)\end{array}$ & $\begin{array}{l}\text { Hor \& post SCC \& } \\
\text { utriculus }(15 \%, 3 / 20)\end{array}$ & $\mathrm{NaN}^{*}$ \\
\hline $\begin{array}{l}\text { Acute cochleo- } \\
\text { vestibular neuropathy } \\
(\mathrm{n}=20)\end{array}$ & 19 & 11 & 17 & 0.61 & $5(25.0)$ & $2(10.0)$ & & $4(20.0)$ & $\begin{array}{l}70 \% \text { vs. } 55 \%: \\
\mathrm{p}=0.514\end{array}$ & $\begin{array}{l}\text { All } 5 \text { sensors }(33 \% \text {, } \\
2 / 6)\end{array}$ & $\mathrm{NaN}^{*}$ & $\mathrm{NaN}^{*}$ \\
\hline $\begin{array}{l}\text { Unilateral vestibular } \\
\text { schwannoma }(\mathrm{n}=55)\end{array}$ & 47 & 20 & 43 & 0.44 & $5(31.3)$ & $2(12.5)$ & $2(12.5)$ & $7(43.8)$ & $\begin{array}{l}44 \% \text { vs. } 25 \%: \\
p=0.458\end{array}$ & $\begin{array}{l}\text { All SCCs \& utriculus } \\
(22 \%, 2 / 9)\end{array}$ & $\begin{array}{l}\text { Hor \& post SCC, } \\
\text { utriculus \& sacculus } \\
(22 \%, 2 / 9)\end{array}$ & $\begin{array}{l}\text { Post \& ant SCC } \\
(22 \%, 2 / 9)\end{array}$ \\
\hline $\begin{array}{l}\text { Cerebello-pontine angle } \\
\text { mass other than } \\
\text { schwannoma }(n=9)\end{array}$ & 9 & 3 & 7 & 0.38 & $3(33.3)$ & $2(22.2)$ & $4(44,4)$ & $0(0.0)$ & $\begin{array}{l}56 \% \text { vs. } 67 \%: \\
p=1.000\end{array}$ & $\begin{array}{l}\text { Hor SCC only }(25 \% \text {, } \\
4 / 16)\end{array}$ & $\begin{array}{l}\text { Post SCC only (19\%, } \\
3 / 16)\end{array}$ & $\begin{array}{l}\text { Hor \& post SCC \& } \\
\text { utriculus }(13 \%, \\
2 / 16)\end{array}$ \\
\hline $\begin{array}{l}\text { Episodic vestibular } \\
\text { syndrome }(\mathrm{n}=46)\end{array}$ & 36 & 6 & 20 & 0.21 & $2(25.0)$ & $0(0.0)$ & $2(25.0)$ & $4(50.0)$ & $\begin{array}{l}50 \% \text { vs. } 25 \%: \\
\text { p }=0.082\end{array}$ & $\begin{array}{l}\text { Hor SCC only }(33 \% \text {, } \\
15 / 46)\end{array}$ & $\begin{array}{l}\text { Hor SCC \& utriculus } \\
(13 \%, 6 / 46)\end{array}$ & $\begin{array}{l}\text { Post SCC only } \\
(13 \%, 6 / 46)\end{array}$ \\
\hline $\begin{array}{l}\text { Menière's disease } \\
(\mathrm{n}=16)\end{array}$ & 12 & 2 & 8 & 0.20 & $1(14.3)$ & $0(0.0)$ & $0(0.0)$ & $6(85.7)$ & $\begin{array}{l}14 \% \text { vs. } 0 \%: \\
p=1.000\end{array}$ & $\begin{array}{l}\text { Hor SCC only }(57 \% \text {, } \\
4 / 7)\end{array}$ & $\begin{array}{l}\text { Post SCC only (29\%, } \\
2 / 7)\end{array}$ & $\begin{array}{l}\text { Hor SCC \& } \\
\text { utriculus }(14 \%, 1 / 7)\end{array}$ \\
\hline Gait imbalance $(n=7)$ & 5 & 0 & 2 & 0.00 & $1(16.7)$ & $0(0.0)$ & $3(50.0)$ & $2(33.3)$ & $\begin{array}{l}67 \% \text { vs. } 50 \%: \\
p=1.000\end{array}$ & $\begin{array}{l}\text { All } 5 \text { sensors }(25 \%, \\
2 / 8)\end{array}$ & $\begin{array}{l}\text { Horizontal SCC and } \\
\text { utriculus }(25 \%, 2 / 8)\end{array}$ & $\begin{array}{l}\text { Hor SCC only }(25 \% \text {, } \\
2 / 8)\end{array}$ \\
\hline Central causes $(\mathrm{n}=6)$ & 4 & 0 & 2 & 0.00 & $0(0.0)$ & $1(16.7)$ & $1(16.7)$ & $4(66.7)$ & $\begin{array}{l}17 \% \text { vs. } 33 \%: \\
p=0.454\end{array}$ & $\begin{array}{l}\text { Hor SCC only }(50 \% \text {, } \\
3 / 6)\end{array}$ & $\mathrm{NaN}^{*}$ & $\mathrm{NaN}^{*}$ \\
\hline All groups $(\mathrm{n}=302)$ & $\begin{array}{l}264 \\
(87.4 \%)\end{array}$ & $\begin{array}{l}114 \\
(37.6 \%)\end{array}$ & $\begin{array}{l}143 \\
(47.4 \%)\end{array}$ & 0.56 & $98(32.5)$ & $21(7.0)$ & 77 (25.5) & $106(35.1)$ & $\begin{array}{l}58 \% \text { vs. } 32 \%: \\
\text { p<0.001 }\end{array}$ & $\begin{array}{l}\text { Hor SCC only }(18 \% \text {, } \\
53 / 302)\end{array}$ & $\begin{array}{l}\text { Hor \& ant SCC \& } \\
\text { utriculus }(12 \%, \\
37 / 302)\end{array}$ & $\begin{array}{l}\text { All } 5 \text { sensors }(12 \% \text {, } \\
35 / 302)\end{array}$ \\
\hline
\end{tabular}

* Too few numbers to determine.

Abbreviations: ant=anterior; hor=horizontal; post=posterior. 


\section{FIGURES}

\section{Figure 1}

Flow diagram illustrating the patient selection process (modified after ${ }^{50}$ ).
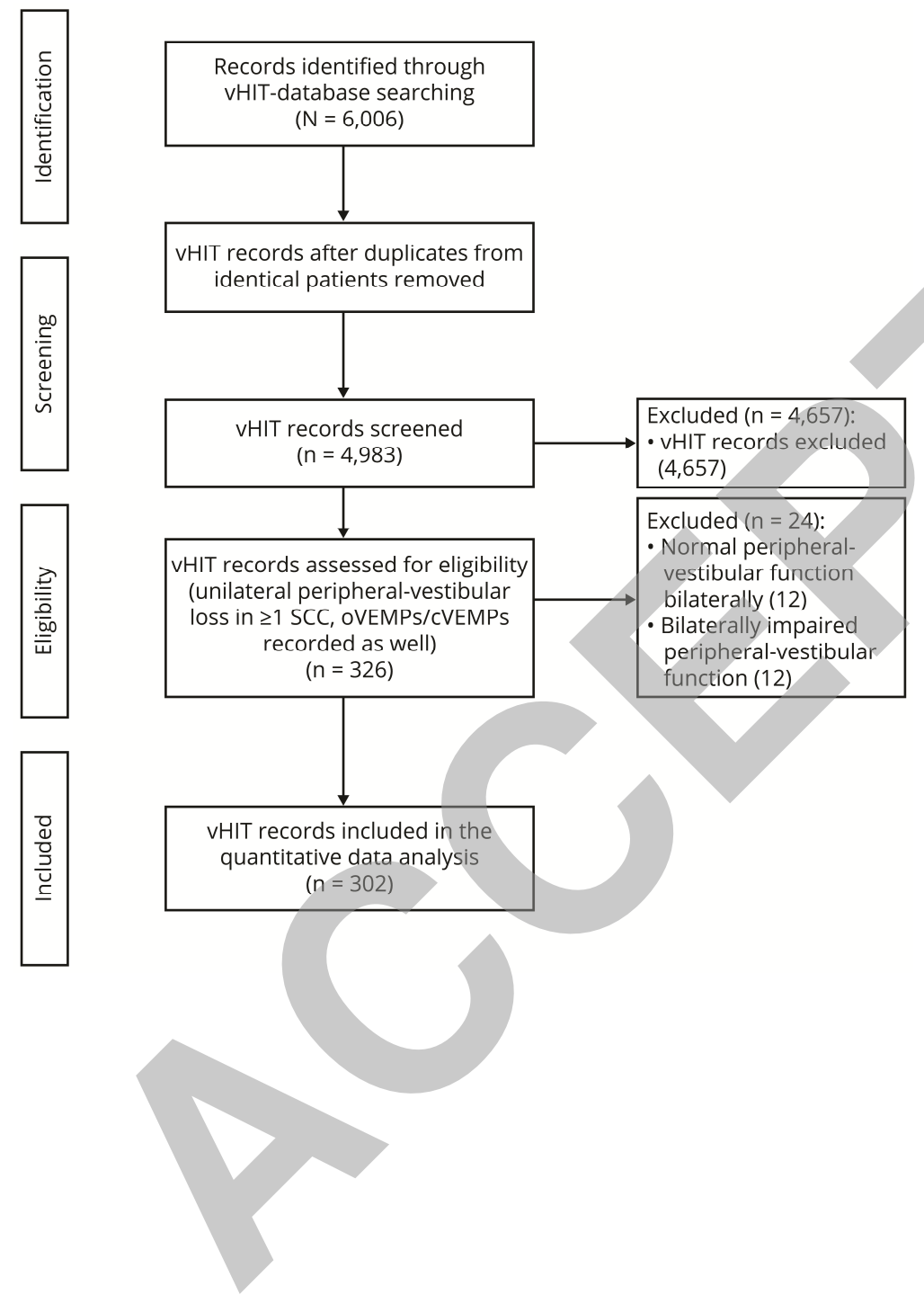
Figure 2

Vestibular mapping in a single patient with acute left-sided vestibular neuropathy. Otolith testing indicated left-sided utricular impairment (oVEMPs, panel A) based on three repetitions (only two are shown here) with an average asymmetry ratio of $51 \%$. Air-conducted cVEMPs (panel B) obtained at an intensity of 95db HL (hearing loss) were bilaterally intact with an asymmetry ratio of $2 \%$. In panel $\mathrm{C}$, eye velocity traces (in green) and head velocity traces (in blue for head turns to the left and in red for head turns to the right) are plotted against time for each SCC. Note that eye velocity traces were inverted for better visualization and comparison with the head velocity traces. Catch-up saccades (in the left horizontal and the left anterior canal) are indicated by the black arrows. With the ipsilesional horizontal and anterior SCC and the utriculus being impaired and the ipsilesional posterior SCC and the sacculus being preserved, this subject was assigned to cluster E in the cluster analysis (see Figure 4). 


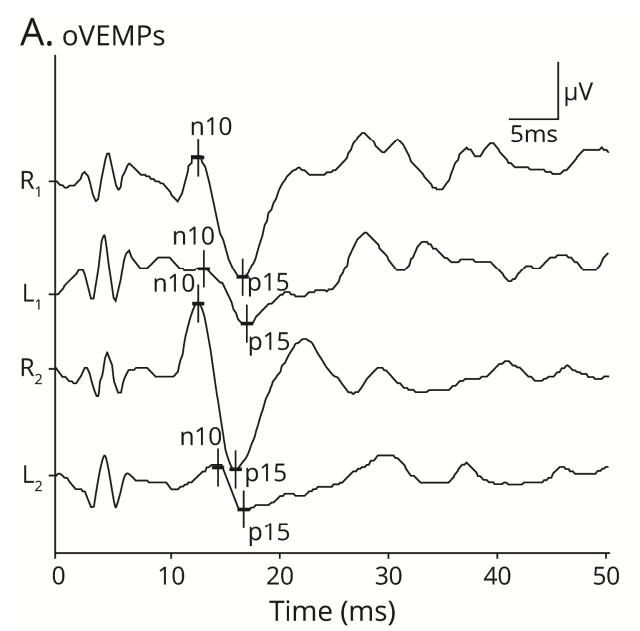

B. cVEMPs
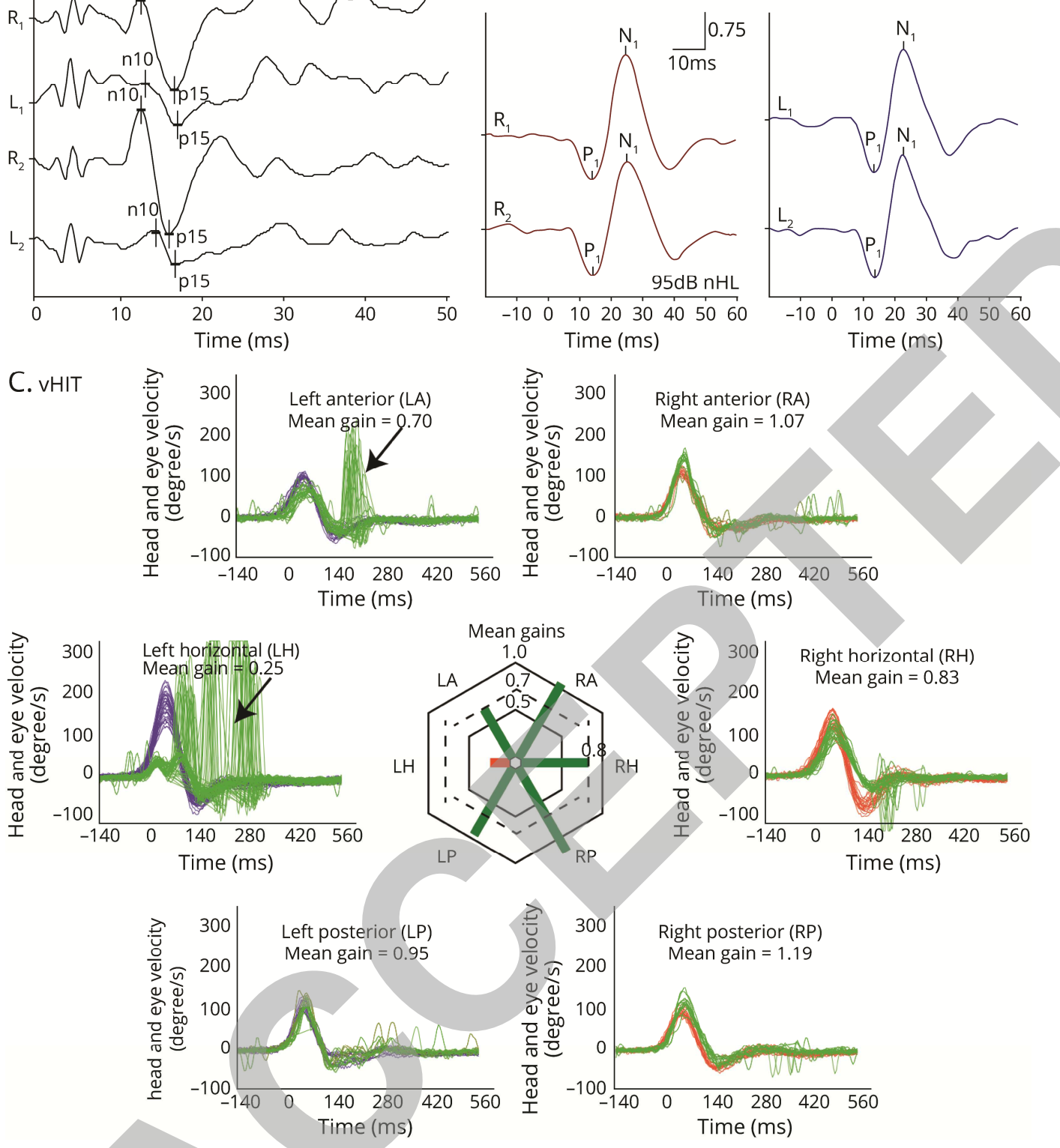
Figure 3

\section{Quantitative assessment of peripheral-vestibular function and spectrum of impairment-}

patterns. In Panel A, the percentage of patients with normal function (dark grey shaded areas) and with hypofunction (light grey shaded areas) for the different SCCs are illustrated in a hexplot. Mean gains including the upper 95\%-CI (end of error bar indicated by a dashed line) and 1SD (end of error bar indicated by a solid line) (panel B) and cumulative saccadic amplitudes (mean including upper 95\%-CI and 1 SD) (panel C) of all patients $(n=302)$ are shown separately, with values from the affected (right) side and the unaffected (left) side indicated by black bars. Gain values (from 0 to 1 ) and cumulative saccadic amplitudes $(\% /$ trial, from 0 to 3 ) are provided along the different hexagons. Cut-off values for reduced gains and for abnormally increased cumulative saccade-amplitudes are indicated by dashed lines. In Panel D, a polar histogram plot illustrates the numbers of the different combinations of semicircular canal and otolith impairment for all 302 UVL-patients. Which SCCs are deficient is indicated in the outer circle; in the inner circle the status of the otolith organs is provided for each combination of SCC impairment. With either utricular and saccular impairment (U\&S), isolated utricular (U) or saccular (S) impairment or functionally intact otolith organs $(\cdot)$ ). In Panel E, the mean number (including 1 SD (end of error bar indicated by a solid line) and the upper 95\%-CI (end of error bar indicated by a dashed line)) of affected sensors on the side with abnormal SCC function for all subgroups with $n \cdot 5$, based on reviewers' ratings for SCC function and on response amplitude asymmetry for oVEMPs and cVEMPs are shown. Abbreviations: ACVN=acute cochleo-vestibular neuropathy; AVN=acute vestibular neuropathy, CPA=cerebello-pontine angle; EVS=episodic vestibular syndrome; MD=Menière's disease; VS=vestibular schwannoma. Only statistically significant differences in p-values (marked with a “*”) are shown and results were grouped for 
illustrative purposes, providing the largest $\mathrm{p}$-value and by indicating that the other $\mathrm{p}$-values in this group were equal or smaller.
A. Relative frequency of SCCS
B. Gains
C. Cumulative saccade amplitudes (deg/trial)
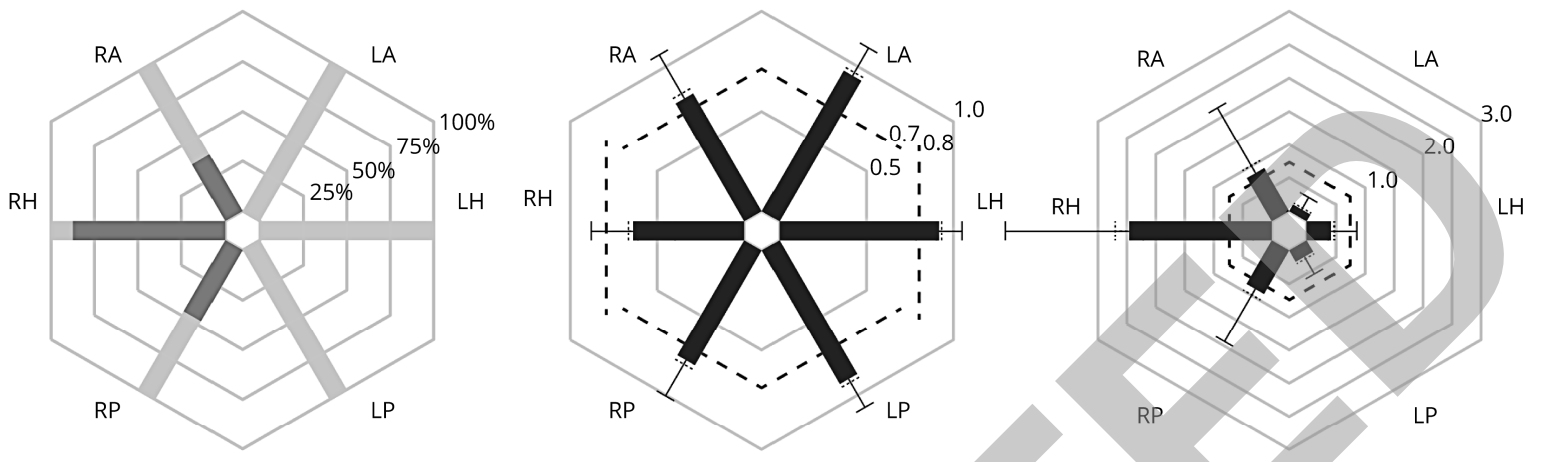

D. Frequency of different combinations

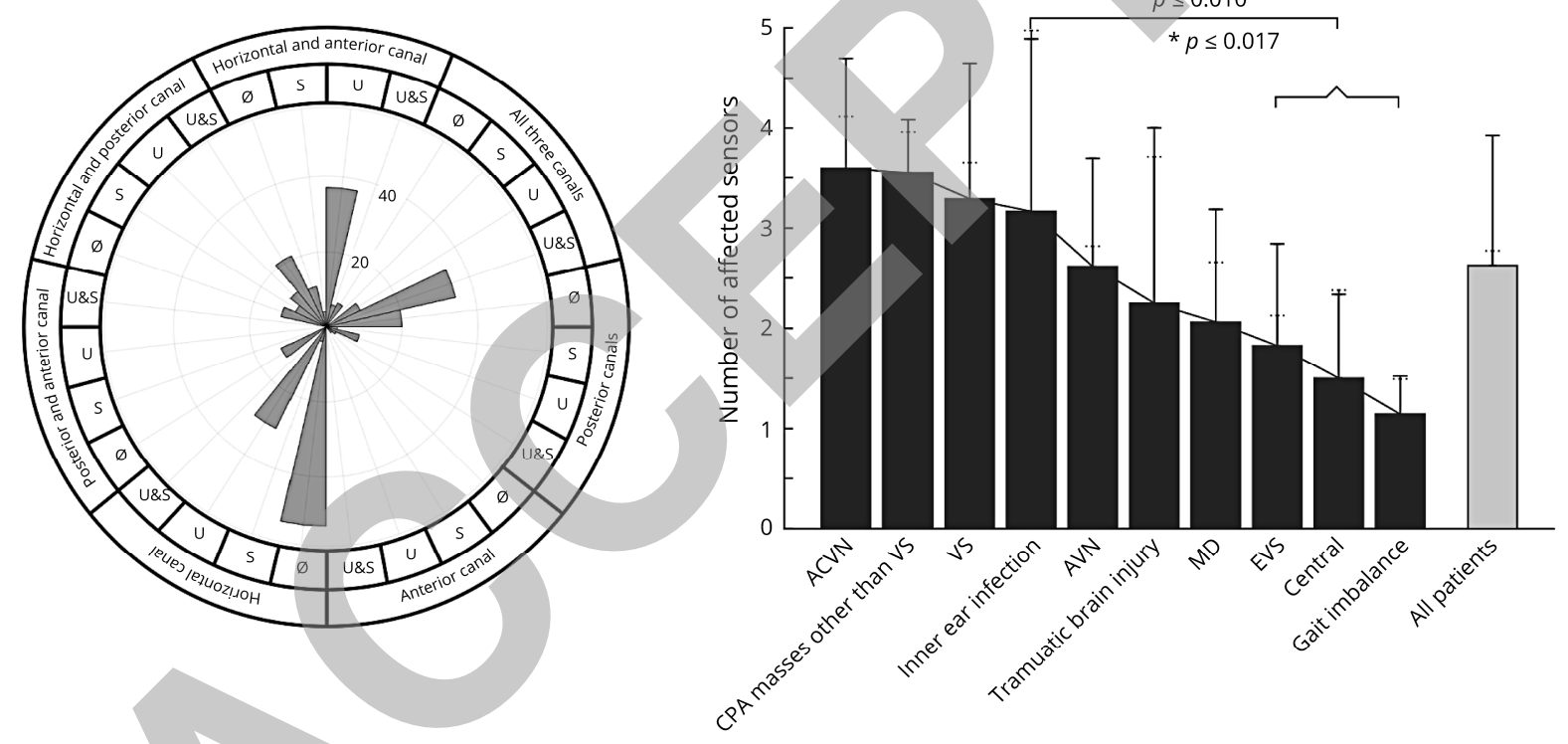




\section{Figure 4}

Polar histogram plots illustrating the distribution of impairment patterns in the subgroups. Here the absolute numbers of the different combinations of semicircular canal and otolith impairment are illustrated in separate polar histogram plot for all subgroups with n - 5 (panels A to I). See legend of figure 3D for further details.

A. Acute vestibular neuropathy $(n=113)$

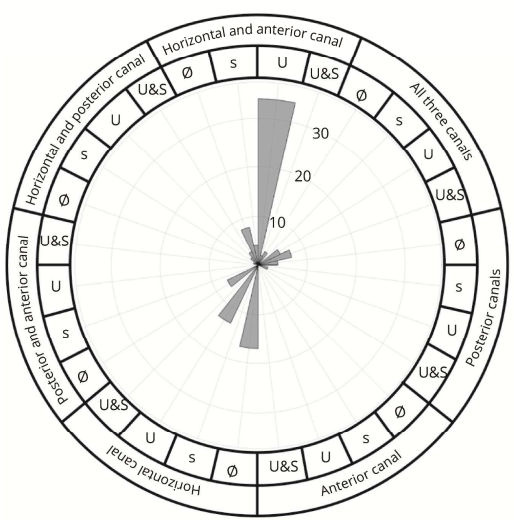

D. CPA mass other than vest. schwannoma $(n=9)$ E. Menière disease $(n=16)$

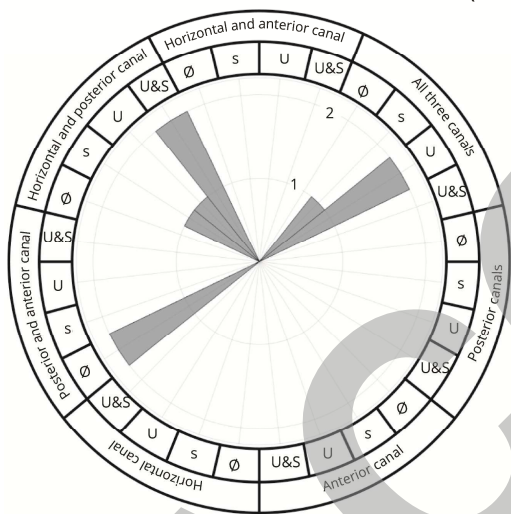

G. Inner ear infection $(n=6)$

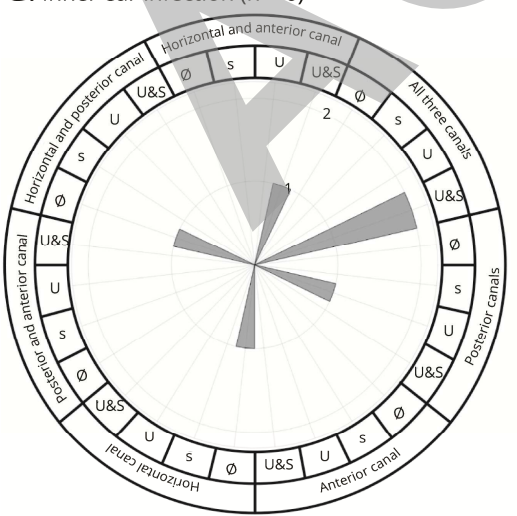

B. Acute cochleo-vestibular neuropathy $(n=20)$

C. Unilateral vestibular schwannoma $(n=55)$
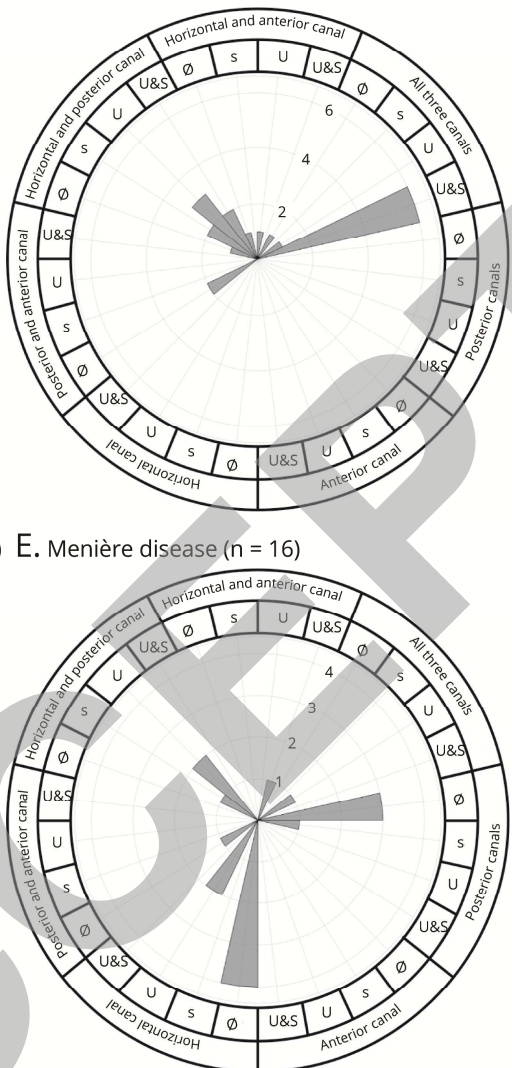

H. Episodic vestibular syndrome $(n=46)$

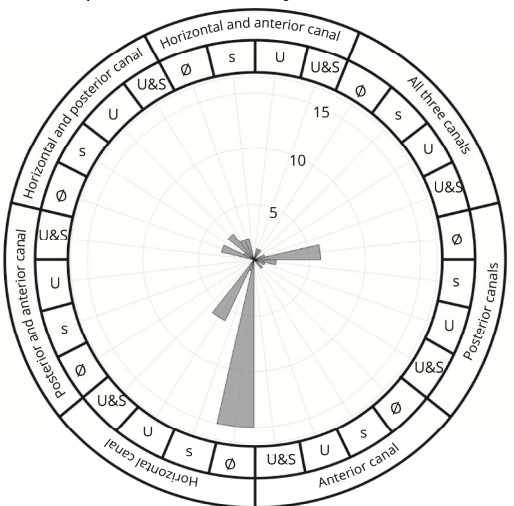

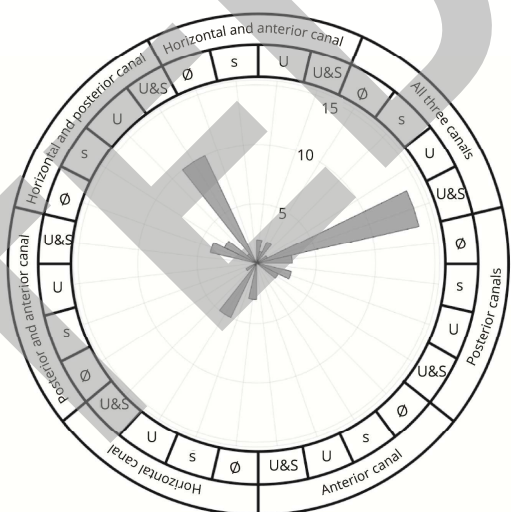

F. Traumatic brain injury $(n=8)$

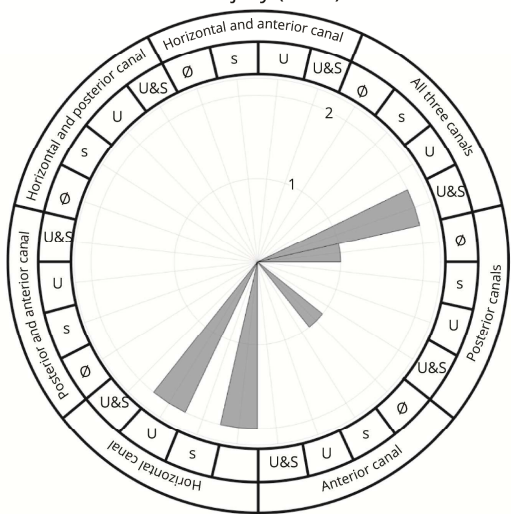

I. Gait imbalance of unclear origin $(n=7)$

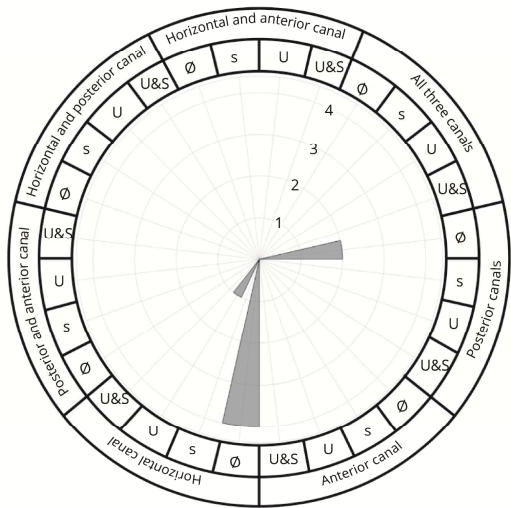

Figure 5 


\section{Hierarchical cluster analysis based on the functional integrity of the vestibular sensors.}

A heat map indicates the functional state (from intact (=blue) to deficient (=red)) for each vestibular end organ $(n=5)$ and patient $(n=302)$ on the affected side. The heat map was clustered by Euclidean distance (see methods section for details). Diagnosis in each patient is provided along the $\mathrm{x}$-axis. Cluster dendrograms indicate those patients ( $\mathrm{x}$-axis) and vestibular end organs (y-axis) that are the least different, as these groups cluster together first. Cluster analysis identified seven clusters with at least 25 patients (nodes A-G), which are all marked with black bars. Abbreviations: ACVN=acute cochleo-vestibular neuropathy, AVN=acute vestibular neuropathy, bilat.=bilateral, BPPV=benign paroxysmal positional vertigo, $\mathrm{CPA}=$ cerebello-pontine angle, EVS=episodic vestibular syndrome, IE=inner ear, $\mathrm{MD}=$ Menière's disease, $\mathrm{NF} 2=$ neurofibromatosis type 2, PNP=polyneuropathy, SSCDS=superior semicircular canal dehiscence syndrome, unilat.=unilateral, $\mathrm{VP}=$ vestibular paroxysmia, VS=vestibular schwannoma

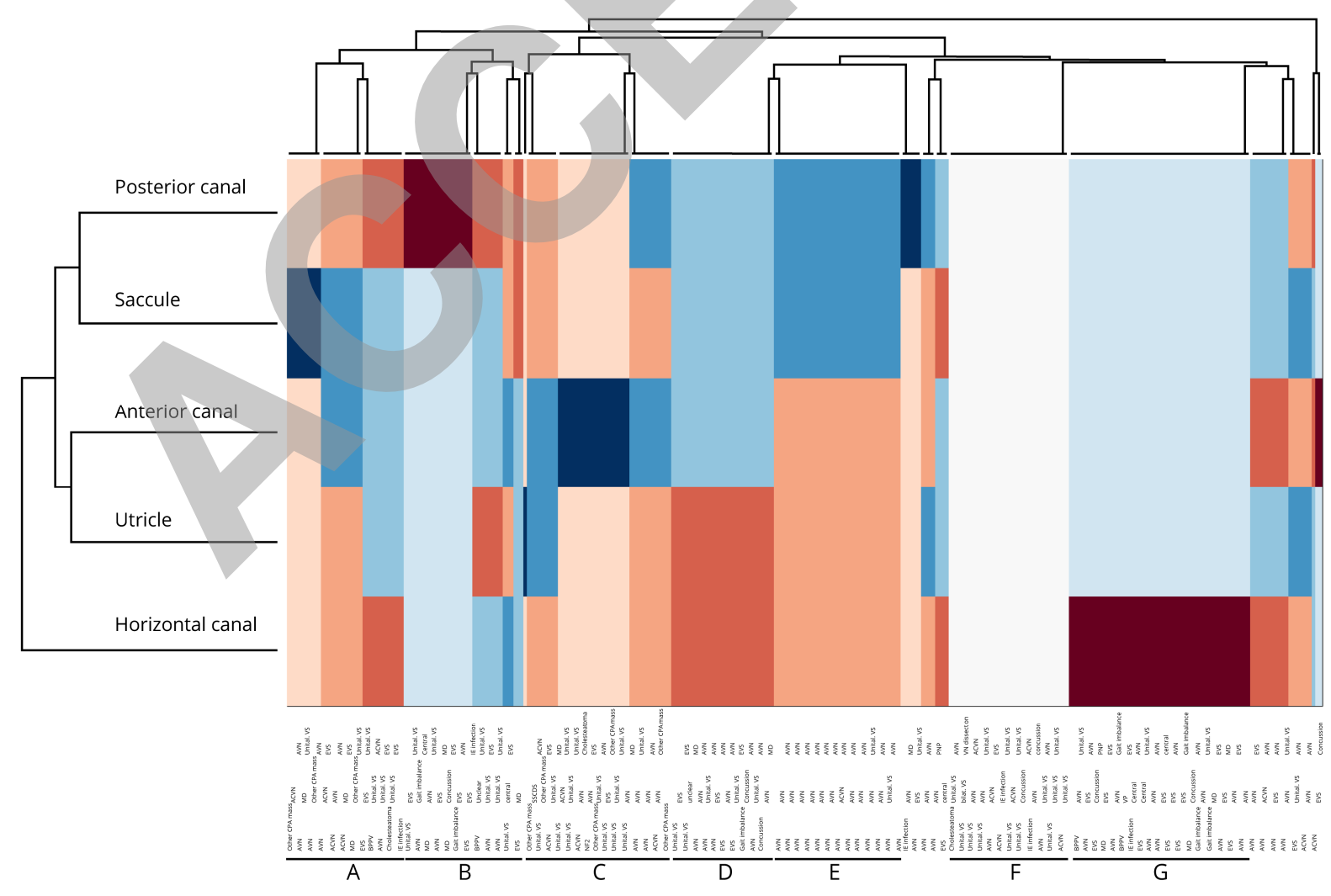




\section{APPENDIX}

\section{Appendix 1: Authors}

\begin{tabular}{|l|l|l|}
\hline Name & Location & contribution \\
\hline $\begin{array}{l}\text { Alexander A. } \\
\text { Tarnutzer MD }\end{array}$ & Cantonal Hospital of Baden & $\begin{array}{l}\text { Drafted the manuscript, analyzed the data } \\
\text { and conceived of the study; revised the } \\
\text { manuscript for intellectual content. }\end{array}$ \\
\hline $\begin{array}{l}\text { Christopher J. } \\
\text { Bockisch PhD }\end{array}$ & University Hospital Zurich & $\begin{array}{l}\text { helped in the data analysis and } \\
\text { interpretation; revised the manuscript for } \\
\text { intellectual content. }\end{array}$ \\
\hline $\begin{array}{l}\text { Klena Buffone } \\
\text { MD }\end{array}$ & University Hospital Zurich & $\begin{array}{l}\text { performed the data collection; revised the } \\
\text { manuscript for intellectual content. }\end{array}$ \\
\hline
\end{tabular}




\section{REFERENCES}

1. Newman-Toker DE, Hsieh YH, Camargo CA, Jr., Pelletier AJ, Butchy GT, Edlow JA. Spectrum of dizziness visits to US emergency departments: cross-sectional analysis from a nationally representative sample. Mayo Clin Proc 2008;83:765-775.

2. Kroenke K, Jackson JL. Outcome in general medical patients presenting with common symptoms: a prospective study with a 2-week and a 3-month follow-up. Fam Pract 1998;15:398-403.

3. Bhattacharyya N, Gubbels SP, Schwartz SR, et al. Clinical Practice Guideline: Benign Paroxysmal Positional Vertigo (Update). Otolaryngol Head Neck Surg 2017;156:S1-S47.

4. Halmagyi GM, Curthoys IS. A clinical sign of canal paresis. Arch Neurol $1988 ; 45: 737-739$.

5. Halmagyi GM, Chen L, MacDougall HG, Weber KP, McGarvie LA, Curthoys IS. The Video Head Impulse Test. Front Neurol 2017;8:258.

6. Rosengren SM, Colebatch JG, Young AS, Govender S, Welgampola MS. Vestibular evoked myogenic potentials in practice: Methods, pitfalls and clinical applications. Clin Neurophysiol Pract 2019;4:47-68.

7. Curthoys IS. The new vestibular stimuli: sound and vibration-anatomical, physiological and clinical evidence. Exp Brain Res 2017;235:957-972.

8. Taylor RL, Kong J, Flanagan S, et al. Prevalence of vestibular dysfunction in patients with vestibular schwannoma using video head-impulses and vestibular-evoked potentials. J Neurol 2015;262:1228-1237. 
9. Constanzo F, Teixeira BCA, Sens P, Ramina R. Video Head Impulse Test in Vestibular Schwannoma: Relevance of Size and Cystic Component on Vestibular Impairment. Otol Neurotol 2019;40:511-516.

10. MacDougall HG, McGarvie LA, Halmagyi GM, Curthoys IS, Weber KP. Application of the video head impulse test to detect vertical semicircular canal dysfunction. Otol Neurotol 2013;34:974-979.

11. Poretti A, Palla A, Tarnutzer AA, et al. Vestibular impairment in patients with Charcot-Marie-tooth disease. Neurology 2013;80:2099-2105.

12. Blanquet M, Petersen JA, Palla A, et al. Vestibulo-cochlear function in inflammatory neuropathies. Clin Neurophysiol 2018;129:863-873.

13. Weber KP, Rosengren SM, Michels R, Sturm V, Straumann D, Landau K. Single motor unit activity in human extraocular muscles during the vestibulo-ocular reflex. J Physiol 2012;590:3091-3101.

14. McCaslin DL, Fowler A, Jacobson GP. Amplitude normalization reduces cervical vestibular evoked myogenic potential (cVEMP) amplitude asymmetries in normal subjects: proof of concept. J Am Acad Audiol 2014;25:268-277.

15. Rosengren SM. Effects of muscle contraction on cervical vestibular evoked myogenic potentials in normal subjects. Clin Neurophysiol 2015;126:2198-2206.

16. Rosengren SM, Welgampola MS, Colebatch JG. Vestibular evoked myogenic potentials: past, present and future. Clin Neurophysiol 2010;121:636-651.

17. Weber KP, Rosengren SM. Clinical utility of ocular vestibular-evoked myogenic potentials (oVEMPs). Curr Neurol Neurosci Rep 2015;15:22. 
18. Macdougall HG, McGarvie LA, Halmagyi GM, Curthoys IS, Weber KP. The video Head Impulse Test (vHIT) detects vertical semicircular canal dysfunction. PLoS One 2013;8:e61488.

19. Tarnutzer AA, Bockisch CJ, Buffone E, Weiler S, Bachmann LM, Weber KP. Disease-specific sparing of the anterior semicircular canals in bilateral vestibulopathy. Clin Neurophysiol 2016;127:2791-2801.

20. Weber KP, Aw ST, Todd MJ, McGarvie LA, Curthoys IS, Halmagyi GM. Horizontal head impulse test detects gentamicin vestibulotoxicity. Neurology 2009;72:1417-1424.

21. Weber KP, Aw ST, Todd MJ, McGarvie LA, Curthoys IS, Halmagyi GM. Head impulse test in unilateral vestibular loss: vestibulo-ocular reflex and catch-up saccades. Neurology 2008;70:454-463.

22. MacDougall HG, McGarvie LA, Halmagyi GM, et al. A new saccadic indicator of peripheral vestibular function based on the video head impulse test. Neurology 2016;87:410418.

23. Committee on Hearing and Equilibrium guidelines for the diagnosis and evaluation of therapy in Meniere's disease. American Academy of Otolaryngology-Head and Neck Foundation, Inc. Otolaryngol Head Neck Surg 1995;113:181-185.

24. Ward BK, Carey JP, Minor LB. Superior Canal Dehiscence Syndrome: Lessons from the First 20 Years. Front Neurol 2017;8:177.

25. Strupp M, Magnusson M. Acute Unilateral Vestibulopathy. Neurol Clin 2015;33:669685. 
26. Cohen J. A coefficient for agreement for nominal scales. Educ Psychol Meas 1960;20:37-46.

27. Curthoys IS. A critical review of the neurophysiological evidence underlying clinical vestibular testing using sound, vibration and galvanic stimuli. Clin Neurophysiol 2010;121:132-144.

28. Ward BK, Bockisch CJ, Caramia N, Bertolini G, Tarnutzer AA. Gravity dependence of the effect of optokinetic stimulation on the subjective visual vertical. J Neurophysiol 2017;117:1948-1958.

29. Weinstein JN. Biochemistry. A postgenomic visual icon. Science 2008;319:17721773.

30. Wilkinson L, Friendly M. The History of the Cluster Heat Map. The American Statistician 2009;63:179-184.

31. Council on Physical Therapy AMA. Tentative standard procedures for evaluating the percentage of useful hearing loss in medicolegal cases. JAMA 1942;119:1108-1109.

32. Taylor RL, McGarvie LA, Reid N, Young AS, Halmagyi GM, Welgampola MS. Vestibular neuritis affects both superior and inferior vestibular nerves. Neurology 2016;87:1704-1712.

33. Magliulo G, Gagliardi S, Ciniglio Appiani M, Iannella G, Re M. Vestibular neurolabyrinthitis: a follow-up study with cervical and ocular vestibular evoked myogenic potentials and the video head impulse test. Ann Otol Rhinol Laryngol 2014;123:162-173.

34. Aw ST, Fetter M, Cremer PD, Karlberg M, Halmagyi GM. Individual semicircular canal function in superior and inferior vestibular neuritis. Neurology 2001;57:768-774. 
35. Tarnutzer AA, Bockisch CJ, Buffone E, Weber KP. Association of posterior semicircular canal hypofunction on video-head-impulse testing with other vestibulo-cochlear deficits. Clin Neurophysiol 2017;128:1532-1541.

36. Buki B, Hanschek M, Junger H. Vestibular neuritis: Involvement and long-term recovery of individual semicircular canals. Auris Nasus Larynx 2017;44:288-293.

37. Lee JY, Park JS, Kim MB. Clinical Characteristics of Acute Vestibular Neuritis According to Involvement Site. Otol Neurotol 2019;40:797-805.

38. Fukushima M, Oya R, Nozaki K, et al. Vertical head impulse and caloric are complementary but react opposite to Meniere's disease hydrops. Laryngoscope 2019;129:1660-1666.

39. Zulueta-Santos C, Lujan B, Manrique-Huarte R, Perez-Fernandez N. The vestibuloocular reflex assessment in patients with Meniere's disease: examining all semicircular canals. Acta Otolaryngol 2014;134:1128-1133.

40. ElSherif M, Reda MI, Saadallah H, Mourad M. Video head impulse test (vHIT) in migraine dizziness. J Otol 2018;13:65-67.

41. Yoo MH, Kim SH, Lee JY, Yang CJ, Lee HS, Park HJ. Results of video head impulse and caloric tests in 36 patients with vestibular migraine and 23 patients with vestibular neuritis: a preliminary report. Clin Otolaryngol 2016;41:813-817.

42. Yollu U, Uluduz DU, Yilmaz M, et al. Vestibular migraine screening in a migrainediagnosed patient population, and assessment of vestibulocochlear function. Clin Otolaryngol 2017;42:225-233. 
43. Shin BS, Oh SY, Kim JS, et al. Cervical and ocular vestibular-evoked myogenic potentials in acute vestibular neuritis. Clin Neurophysiol 2012;123:369-375.

44. Kim JS, Kim HJ. Inferior vestibular neuritis. J Neurol 2012;259:1553-1560.

45. Chen L, Xu H, Wang WQ, Zhang QQ, Lv QY, Song XC. Evaluation of the otolith function using c/oVEMPs in patients with Meniere's disease. J Otolaryngol Head Neck Surg 2016;45:39.

46. Okumura T, Imai T, Takimoto Y, et al. Assessment of endolymphatic hydrops and otolith function in patients with Meniere's disease. Eur Arch Otorhinolaryngol 2017;274:1413-1421.

47. Jerin C, Maxwell R, Gurkov R. High-Frequency Horizontal Semicircular Canal Function in Certain Meniere's Disease. Ear Hear 2019;40:128-134.

48. de Waele C, Huy PT, Diard JP, Freyss G, Vidal PP. Saccular dysfunction in Meniere's disease. Am J Otol 1999;20:223-232.

49. Kinoshita M, Iwasaki S, Fujimoto C, et al. Ocular vestibular evoked myogenic potentials in response to air-conducted sound and bone-conducted vibration in vestibular schwannoma. Otol Neurotol 2013;34:1342-1348.

50. Moher D, Liberati A, Tetzlaff J, Altman DG, Group P. Preferred reporting items for systematic reviews and meta-analyses: the PRISMA statement. PLoS Med 2009;6:e1000097. 


\section{Neurology}

Vestibular mapping in patients with unilateral peripheral-vestibular deficits

Alexander A. Tarnutzer, Christopher J. Bockisch, Elena Buffone, et al.

Neurology published online September 10, 2020

DOI 10.1212/WNL.0000000000010812

This information is current as of September 10, 2020

$\begin{array}{ll}\text { Updated Information \& } & \text { including high resolution figures, can be found at: } \\ \text { Services } & \text { http://n.neurology.org/content/early/2020/09/10/WNL.0000000000010 } \\ & \text { Thill } \\ \text { This article, along with others on similar topics, appears in the } & \text { following collection(s): } \\ & \text { All clinical neurophysiology } \\ & \text { http://n.neurology.org/cgi/collection/all_clinical_neurophysiology } \\ \text { Clinical neurology examination } & \text { http://n.neurology.org/cgi/collection/clinical_neurology_examination } \\ & \text { Vertigo } \\ & \text { http://n.neurology.org/cgi/collection/vertigo } \\ & \text { Information about reproducing this article in parts (figures,tables) or in } \\ & \text { its entirety can be found online at: } \\ & \text { http://www.neurology.org/about/about_the_journal\#permissions } \\ & \text { Information about ordering reprints can be found online: } \\ \text { Permissions \& Licensing } & \text { http://n.neurology.org/subscribers/advertise }\end{array}$

Neurology ${ }^{\circledR}$ is the official journal of the American Academy of Neurology. Published continuously since 1951, it is now a weekly with 48 issues per year. Copyright (C 2020 American Academy of Neurology. All rights reserved. Print ISSN: 0028-3878. Online ISSN: 1526-632X.

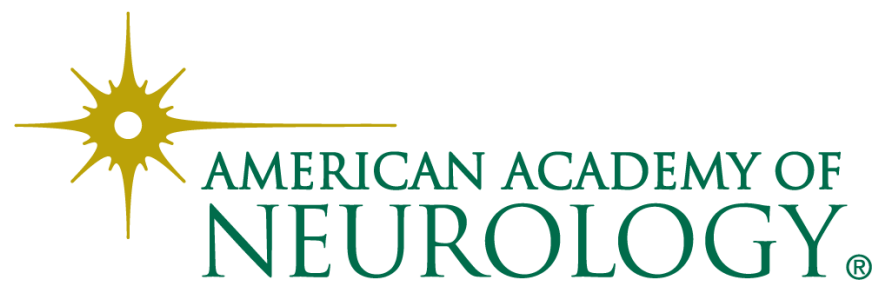

